\title{
SOBRE LA POÉTICA DE LA TRAGEDIA NEOCLÁSICA ESPAÑOLA
}

\author{
Jesús Cañas Murillo \\ Universidad de Extremadura
}

\begin{abstract}
RESUMEN
Este es un estudio de los constituyentes que integran la poética de la tragedia neoclásica española y la individualizan como género. Partiendo de las definiciones teóricas expuestas en $\mathrm{La}$ Poética de Luzán, se desciende a la práctica de los textos para analizar el tratado que en ellos se halla de la acción, los principales recursos que se utilizan, la construcción de los personajes y la identificación de los tipos que le sirven de base, los temas y su forma de tratamiento, el significado, el mensaje que subyace a las obras y que ellas dèsean transmitir. Algunas consideraciones sobre la trayectoria y evolución del género cierran el trabajo.
\end{abstract}

\begin{abstract}
This is a study of the components that integrate the poetics of neoclassical Spanish tragedy and that individualize it as a genre. As of the theoretical definitions displayed in Luzan's Poetics, we descend to the practice of texts, in order to analize the treaty on action found in them, the main resources used, the building of characters, and the identification of the types used as a basis, the themes and their treatment, the meaning, the message underlying the works and that they want to transmit. Some considerations about the trajectory and evolution of the genre close the work.
\end{abstract}

\section{A modo de introducción: antecedentes y génesis de la tragedia neoclási- ca española}

De entre los géneros dramáticos neoclásicos que fueron viendo la luz en el siglo XVIII español, la tragedia fue el primero cronológicamente en aparecer. Antes de la comedia sentimental (Cañas 1994), introducida en primer lugar por Ignacio de Luzán, con su obra La razón contra la moda (1751) -versión de una comedia del francés Nivelle de la Chausée (Le Préjugé à la mode)-, impresa en Madrid en el año 1751. Antes de la comedia de buenas costumbres, iniciada, en 1762, por La Petimetra, de Nicolás Fernández de Moratín (1989). 
Las primeras tragedias neoclásicas españolas, recordemos, surgen a mediados del siglo XVIII. En el año 1750 Agustín Montiano y Luyando difunde Virginia, dentro de su Discurso sobre las tragedias españolas. Poco después, en 1753, el mismo autor publica Ataulfo, al final de su Discurso II. Sobre las tragedias españolas.

Antes se había intentado dar a conocer el género a través de versiones, llamadas traducciones, de piezas extranjeras que a veces habían sido principalmente destinadas a representaciones de carácter cortesano. Algunas ni siquiera llegaron a montarse sobre las tablas. Tal acontece con la Cinna de Corneille, traducida en 1713 por el marqués de San Juan. Iniciaban todas estas obras una costumbre que no se perdería en todo el siglo XVIII, y que dejó muestras de reconocido prestigio como El Británico de Racine, traducida en 1752 por Juan de Trigueros; la Atalía de Voltaire, de 1754, traducida por Eugenio Llaguno; la Semíramis de Voltaire, traducida por Clavijo y Fajardo; la Zaira, traducida en 1765 por Francisco Postigo con el título de Combate de amor y ley ${ }^{1} \ldots$

De todos modos, los primeros textos originales son las dos tragedias, Virginia y Ataulfo de Montiano que antes hemos mencionado.

Los orígenes de este género aparecen muy ligados, como los orígenes de todos los géneros neoclásicos, a la gran polémica sobre el teatro que se fue desarrollando a lo largo de todo el siglo XVIII. En concreto, en este caso, hay que recordar las contestaciones al francés Du Perron, quien, en el prólogo a su antología de teatro español (Extraits de plusieurs pièces du théâtre espagnol, avec des réflexions, et la traduction des endroits les plus remarquables, publicada en París en 1738), había afirmado la incapacidad histórica de los españoles de componer tragedias y comedias clasicistas. Montiano quiso demostrar la falsedad de tales aseveraciones. Escribió sus dos Discursos sobre las tragedias españolas con el deseo de recopilar noticias históricas sobre tragedias clasicistas hechas en España, con el deseo de difundir la preceptiva neoclásica y con el deseo de ofrecer un ejemplo de texto reglado compuesto por él mismo para demostrar que un español sí puede escribir tragedia clasicista y animar a otras personas, afirma, mejor dotadas que él, a seguir su ejemplo y contribuir a la renovación de la escena española del momento. Así surgen Virginia (1750) y Ataulfo (1753), las dos primeras tragedias neoclásicas españolas originales, textos ambos repletos de buena voluntad pero claramente producto de un crítico lleno de buenas intenciones y no de un consumado dramaturgo. No es extraño que solo fuesen difundidos por la imprenta y que nunca llegasen a ser montados en un escenario ${ }^{2}$.

Quedan, pues, los orígenes del género enmarcados en los círculos de intelectuales que pretenden introducirlo, ex novo, en el panorama teatral del momento. La tragedia neoclásica española no es, pues, producto de una evolución o transformación de un género histórico preexistente, a diferencia de otros géneros del momento, como la comedia de espectáculo, tal y como expliqué en otro lugar ${ }^{3}$.

\section{Los objetivos de un estudio}

El género, la tragedia española dieciochista, es un típico producto del neoclasicismo y de la Ilustración. Su configuración y definición se encomiendan a una poética formada por un conjunto de constituyentes esenciales, de caracteres, de rasgos, que pueden ser identificados en 
los textos. De su delimitación general especialmente, y menos de sus modificaciones, nos vamos a ocupar en este trabajo. Partiremos, para ello, de los principios teóricos que se encontraban en la base de la práctica dramática de la tragedia neoclásica española. Descenderemos, después, a la propia práctica dramática concreta, identificando, por apartados diferentes, por grupos específicos (acción, recursos, personajes, temas, significado), los rasgos primordiales que los textos españoles del setecientos poseen en común.

\title{
3. Las definiciones teóricas como base
}

No careció la tragedia neoclásica española, como aconteció igualmente con el resto de los géneros neoclásicos de su época ${ }^{4}$, de definiciones teóricas. Dejando a un lado los trabajos más específicos de Agustín Montiano y Luyando antes mencionados, recordemos los rasgos que Ignacio Luzán, en su celebérrima e importantísima Poética, destaca como peculiares de la misma. Afirma:

\begin{abstract}
la tragedia es una representación dramática de una gran mudanza de fortuna, acaecida a reyes, príncipes y personajes de gran calidad y dignidad, cuyas caídas, muertes, desgracias y peligros exciten terror y compasión en los ánimos del auditorio, y los curen y purguen de estas y otras pasiones, sirviendo de ejemplo y escarmiento a todos, pero especialmente a los reyes y a las personas de mayor autoridad y poder (Luzán 1977: 433).
\end{abstract}

En esas líneas se hallan encerradas características básicas de la tragedia neoclásica española:

Se insiste en que es una "representación dramática", es decir una obra destinada a ser montada sobre un escenario para un público ante el cual los personajes van a exponer sus cuitas y preocupaciones.

En su argumento se incluye "una gran mudanza de fortuna", es decir, se escenifica el paso de la infelicidad a la felicidad y viceversa. La alternancia entre fortunas y adversidades y el paso de la dicha a la desdicha es consubstancial a la tragedia.

Se cuentan hechos acaecidos "a reyes, príncipes y personajes de gran calidad y dignidad", no a personajes de clases inferiores, que son los protagonistas de la comedia y que no deben ser mezclados -a diferencia de lo que acontece en el teatro barroco, en la comedia nueva y en sus derivados dieciochescos, como la comedia de espectáculo-, en papeles principales, con los primeros, con los nobles y los reyes (el constituyente "tragicomedia" de la comedia nueva queda, así, completamente rechazado).

La tragedia debe contribuir a liberar al público de sus pasiones. De ahí que se indique que las "caídas, muertes, desgracias y peligros" de los personajes "exciten terror y compasión en los ánimos del auditorio, y los curen y purguen de estas y otras pasiones". Es decir, se reafirma que debe producirse la catarsis defendida en la poética clásica y clasicista tradicional.

Y todo tiene una intencionalidad didáctica, debe servir "de ejemplo y escarmiento a todos, pero especialmente a los reyes y a las personas de mayor autoridad y poder".

Otros rasgos de definición son identificables en la práctica dramática de los autores, en los textos concretos compuestos por ellos. 


\section{Sobre los constituyentes esenciales}

\subsection{Caracteres de la acción}

La tragedia debe ser respetuosa con la unidades dramáticas tradicionales. El argumento debe contener una sola acción, si bien entendida como unidad de intención. Puede haber varias líneas argumentales, no varias acciones, siempre y cuando todas confluyan en un mismo fin. Tal sucede en Raquel, de García de la Huerta, en la que el asunto central, la introducción de un factor externo que rompe la armonía del reino y de la monarquía, unifica los diversas ramificaciones del asunto base, la intriga amorosa, la intriga política, las distintas visiones de la monarquía...

Todos los hechos deben situarse en un solo lugar, aunque los tratadistas discrepen de cuál debe ser éste. Según los más estrictos, una única habitación de una misma casa (un salón, la estancia de un palacio...). Según otros, varias estancias, varios cuartos, habitaciones, de una misma mansión. Según otros, lugares próximos de una misma ciudad (tal sucede en $\mathrm{Nu}$ mancia destruida, de López de Ayala, por ejemplo).

Y todo debe transcurrir en una misma unidad temporal, sea ésta el tiempo que dura la representación (entre dos y cuatro horas), el tiempo transcurrido desde que sale el sol hasta que se oculta (unas doce horas), o desde que sale hasta que vuelve a salir (veinticuatro horas).

Los argumentos deben ser históricos, aunque los hechos que en ellos se incluyen no necesariamente han de ser tomados de la realidad. Pueden ser inventados, pero situados en épocas del pasado, no en la realidad contemporánea. Con ello se evita el apasionamiento que produce en el espectador la contemplación de acontecimientos temporalmente próximos a él. Con ello se pretende que el público observe los sucesos con más imparcialidad, con lejanía, y pueda así recibir mejor la enseñanza, esta sí aplicable a la realidad contemporánea, que a través de ellos se transmite.

En los argumentos se pueden utilizar diversas fuentes de inspiración. Los hechos que se escenifican son ubicados en la antigüedad, casi siempre clásica (Virginia, de Montiano; Lucrecia, de Nicolás Fernández de Moratín; Agamenón vengado, de García de la Huerta...); en la época medieval (Hormesinda, de Nicolás Fernández de Moratín; Raquel, de García de la Huerta; Don Sancho García, de Cadalso; La muerte de Munuza, de Jovellanos; Pelayo, de Quintana...); en paises exóticos, orientales (Xayra, o La fe triunfante del amor y cetro, de García de la Huerta; Solaya, de Cadalso...); en América (Atahualpa, de Cristóbal Cortés...). Se da así paso a los diferentes tipos de argumentos detectables en la tragedia neoclásica española: de historia antigua, de historia medieval, de tema oriental, exótico, de tema americano.

En la construcción de los argumentos debe respetarse la norma de la verosimilitud. La realidad no ha de ser presentada como tal (hay hechos reales que pueden resultar inverosímiles y que, por lo tanto, deben ser rechazados), sino como suele ser, e incluso, como es conveniente que sea.

\subsection{Recursos de composición}

Varios son los recursos dramáticos que encontramos más reiteradamente usados en las tragedias neoclásicas españolas. 
Así, la introducción "in medias res", necesaria dado el uso de la unidad de tiempo que se impone. Los dramaturgos no pueden escenificar la historia completa que presentan. Tienen que dar paso a la tragedia con los hechos iniciados y luego, mediante el recurso de la retrospección, narrar los antecedentes, la "prehistoria" de los hechos. Así consiguen que sea verosímil el desarrollo de unos sucesos determinados en tan corto espacio de tiempo.

El paso de la fortuna a la adversidad, antes mencionado y juzgado consubstancial al género por los tratadistas. Sirve para estructurar el argumento, generar tensión y marcar la evolución de la vida de los personajes.

La anticipación de sucesos, el anuncio previo de acontecimientos que luego pueden tener lugar o que se teme que puedan tener lugar. Con ella se genera tensión y se capta la atención de auditorio. Es medio, también, para hacer surgir la expectación.

Los largos parlamentos y soliloquios que facilitan a los personajes, aparte de relatar sucesos no escenificados (importante función debido al uso de las unidades clásicas que impiden la presentación de todos los hechos importantes para el argumento), la transmisión al espectador de sus propios análisis de la realidad en unos casos, o el análisis, por medio de un monólogo interior - de una conversación del agonista consigo mismo- de la situación en la que se encuentran, o los sentimientos entre los que se debaten, de sus dudas, de sus padecimientos. A veces tal análisis puede ser efectuado por medio de una conversación entre varios de los agonistas. Pueden generar expectación, intriga, ante la actitud definitiva que el agonista puede adoptar.

Los enfrentamientos duales y las oposiciones binarias establecen grupos contrapuestos de hechos y, sobre todo, de personajes, habitualmente divididos en bloques que chocan entre sí, como veremos. Permiten conocer mejor los sucesos y tipos de actuación, y caracterizar más claramente a los agonistas, con el fin de, a través de ellos, ensalzar unas formas de comportamiento y rechazar otras. Es función similar a la que cumple el contraste (enfrentamientos duales y oposiciones binarias son una forma más concreta de contraste), que puede darse entre varios elementos (no sólo dos) a la vez.

La perspectiva múltiple puede ser utilizada para caracterizar personajes o realizar un determinado planteamiento de un tema o de varios temas. Consiste en presentar tema o personaje desde diferentes puntos de vista, -expuestos, en ocasiones, por agonistas distintos-, que pueden contrastar entre sí, pero que también pueden ser complementarios. Con ella se proporciona una visión más completa de tema o personaje al espectador, que recibe así más elementos de juicio, mayor información. Con ella, si se trata de un personaje, se proporciona a este una más amplia caracterización, con lo cual es mejor conocido por el auditorio; si se trata de un tema se proporcionan más datos sobre él o más facetas, con el fin de transmitir un más cabal conocimiento del mismo y permitir, si aparece el contraste, que una de las visiones prevalezca sobre todas las demás y entre a formar parte del significado, del mensaje que se quiere trasladar al espectador.

Análoga función cumple el paralelismo, ya que permite presentar varias visiones de una misma realidad (un tema, unos hechos, un personaje...) para que sea mejor conocida por el público. Con él, los agonistas reciben una caracterización más redonda. La acción queda más completa. Los temas presentan una multiplicidad de facetas que los enriquecen y van a servir de base, al elegirse una de las posibles opciones, si se insertan, para la transmisión de una enseñanza. 
La anagnórisis tiene en la tragedia neoclásica española una especial intervención. Es entendida, como bien lo explica Luzán en su Poética, en sentido amplio, como el paso de lo desconocido a lo conocido:

Agnición o reconocimiento [...] es pasaje improviso del desconocimiento al conocimiento de una persona, o de alguna especial calidad suya, o de algún hecho, de donde resulte la amistad o enemistad de las personas que son destinadas a ser felices o infelices en el drama (Luzán 1977: 470) ${ }^{5}$.

No consiste, pues, solo en el descubrimiento de la verdadera identidad de un individuo. Puede afectar a sucesos, a contenidos, -a temas-, a personajes. Facilita el desarrollo de los sucesos. Puede contribuir al advenimiento del desenlace. Completa la caracterización de un agonista. Permite el correcto conocimiento de un tema. Crea tensión y expectación.

El simbolismo convierte a objetos y personajes en representantes de determinadas nociones abstractas, o determinados ejemplos de comportamiento o de papeles sociales. Guzmán el Bueno, en la tragedia del mismo título escrita por Nicolás Fernández de Moratín, por ejemplo, simboliza al buen vasallo.

Resúmenes didácticos condensan contenidos o partes de la acción con el fin de facilitar al espectador el seguimiento del argumento y la recepción de la enseñanza que a través de él se desea transmitir.

El destino trágico justifica la actuación de algunos agonistas que padecen sus consecuencias, crea momentos de tensión, y provoca la aparición de una corriente de simpatía, en sentido etimológico (sentir en común), entre espectador y personaje y siembra un sentimiento de compasión en el primero por el segundo.

La justicia poética pone de manifiesto que, en todo caso, cada agonista ha de recibir su merecido, premio o castigo, al final de la pieza, según haya sido su actuación, con lo cual se refuerza claramente el didactismo de la obra.

Son todos, y otros que podrían estudiarse -no pretendemos hacer una relación exhaustiva-, recursos de marcado carácter didáctico, que favorecen la transmisión al público de unos determinados contenidos, de una tesis que el autor pretende defender en su creación.

\subsection{Construcción de personajes}

El número de personajes que aparece en las tragedias neoclásicas españolas, no es, en términos generales, muy elevado. Suele girar en torno a ocho. Con ello se cumple con uno de los preceptos que con más frecuente insistencia figura en los textos dieciochescos de preceptiva, empezando por la Poética de Luzán (Luzán 1977: 514-5). Para los neoclásicos es importante esta, aparentemente, simple cuestión numérica, debido a que la restricción acaba con una de las características más generalizadas en los géneros barrocos de cadentes, epigonales, la comedia nueva, el auto sacramental, el entremés, y en los llamados géneros dramáticos populares de la ilustración, la que en otro sitio denominé comedia de espectáculo (Cañas Murillo 1990: 53-63) (de magia, heroica, militar...), el sainete... En todos estos se tiende a la acumulación de personajes. La reducción supone un duro golpe a las prácticas dramáticas de los mismos, que así se ven sustituidas por los usos de los nuevos géneros neoclásicos que los ilustrados desean implantar y generalizar. 
La inclusión de los personajes en las escenas se hace también con especial cuidado de evitar la acumulación. Es, también, consecuencia del respeto a la preceptiva neoclásica que recomienda no incluir más de cuatro personajes en las tablas y evitar que, incluso en esos casos, hablen a la vez más de dos o tres de ellos:

Porque en pasando de tres que hablen, es confusión y embarazo para la representación (Luzán 1977: 514).

Se busca, con todo, la claridad que permita conocer más a los agonistas y facilite la transmisión de una enseñanza concreta. Tan sólo en momentos especialmente relevantes del argumento, y con el fin de destacarlos por contraste con la situación general, se rompe esta tendencia y se tiende a la acumulación. Tal acontece, especialmente, en los desenlaces de las piezas.

La presentación de los agonistas ante el auditorio es especialmente cuidada. Sus caracteres deben ser perfectamente delimitados ante el espectador, para que este pueda comprendorlos bien. Se considera ello especialmente importante debido a que los personajes se convierten en medio esencial de transmitir una enseñanza, una tesis concreta. Son vistos como representantes de cualidades morales o patrióticas, representantes -incluso símbolos, como afirmábamos- de una ideología o de una línea determinada de comportamiento. Por ello, de los personajes no interesa tanto la actuación, como sus reflexiones racionales acerca de sus sufrimientos, de sus padecimientos reales o posibles.

Los personajes se suelen debatir entre sentimientos contrapuestos. Se defiende a los que anteponen la razón a la pasión, el deber a las apetencias. Sobre esta actitud se monta el significado de las obras, el mensaje que contienen. Por eso pueden resultar a veces fríos, calculadores, alejados de sentimientos auténticamente humanos, preocupados por su deber, del cual se convierten en auténticas víctimas.

De los personajes se destaca su papel aleccionador, como bien señaló Antonio Mendoza:

En la elaboración literaria del carácter español como héroe de tragedia no se trató de crear personajes individuales con vivencias y reacciones personales y biográficas, sino que siguiendo la línea moral, creemos, quiso plantearse un elemento aleccionador que sirve de modelo de conducta, y, en consecuencia, los personajes no se recrearon como individualidades psicológicas, sino como síntesis literarias de una colectividad. Y ello, evidentemente, restó valor creativo a las producciones (Mendoza 1981: 369-89).

El lenguaje que utilizan los personajes es en todo momento elevado, tal y como exigía la preceptiva neoclásica. Ya Luzán en su Poética afirmaba:

...como la tragedia no admite sino personas ilustres y grandes, como reyes, príncipes, héroes, etc., su estilo ha de ser alto, grave y sentencioso (Luzán 1977: 509).

Y similares asertos podemos encontrar en textos de Montiano, Nicolás y Leandro Fernández de Moratín... Existe, no obstante, una adecuación entre lenguaje y situación. Si se desarrolla el tema del amor, el lenguaje se torna más lírico, como acontece en Raquel en la conversación que mantienen Raquel y Alfonso en la jornada segunda; o en Xayra, también de García de la Huerta, en el acto tercero, en el diálogo de Xayra y Orosmán. Si aparece el tema 
de la muerte, el lenguaje se hace más dramático, como acaece en los desenlaces de las tres piezas de García de la Huerta. Si se ponen de manifiesto torturas interiores, el lenguaje se llena de exclamaciones y lamentos. Con tal adecuación se persigue y consigue que el texto gane en verosimilitud, una de las preocupaciones básicas de los neoclásicos, como antes hemos afirmado y como bien queda reflejado, por ejemplo, en La Poética de Luzán ${ }^{6}$.

La construcción de los personajes concretos se realiza a partir de un conjunto de tipos específicos. Tipo y personaje constituyen realidades distintas, aunque en los textos pueden coincidir. El tipo es general, abstracto, pertenece a la poética. El personaje es concreto, pertenece a la obra particular, y puede estar diseñado, o no, sobre la base de un tipo o de varios tipos diferentes que en él pueden confluir. El tipo queda definido por una serie de rasgos generales de caracterización y una serie de funciones recurrentes, en las que todo un grupo de agonistas similares llegan a coincidir. El personaje creado sobre el tipo tiene las características y las funciones de este último, pero puede tener también otras específicas que no se identifican con las de aquel, distintas a las suyas, que no son necesariamente recurrentes, sino propias y peculiares del agonista que figura en cada texto en particular. El personaje tiene sexo concreto. Es masculino o femenino. El tipo no siempre. El sexo puede conferirse en el proceso de conversión del tipo en personaje. El personaje tiene, o puede tener, nombre propio. El tipo tiene sólo nombre genérico y generalizador.

Los tipos funcionales que detectamos en la tragedia neoclásica española son los que detallamos a continuación 7 :

El héroe. Se convierte siempre en personaje principal, protagonista de la acción, encargado de una buena parte del desarrollo del argumento. Es valiente, esforzado, deseoso de cumplir su obligación. Puede debatirse en dilemas que le acarrean torturas interiores (amor/obligación, amor/celos, obligación/dificultades de cumplirla....). Es parte fundamental, pues lo provoca, para el advenimiento del desenlace negativo con víctimas de la tragedia. Sobre este tipo se crean Guzmán el Bueno, en Guzmán el Bueno de Nicolás Fernández Moratín; Alfonso VIII en Raquel de García de la Huerta; Pelayo, en La muerte de Munuza de Jovellanos...

La heroína. Se transforma igualmente en personaje principal, protagonista, encargado del desarrollo básico de la acción. Da vida a un personaje fuerte, aunque flaquee a veces atormentado, que se debate en dudas internas (amor/deber; amor/ansias de poder...) o sufre conflictos (obligación/impedimentos...) que le producen desasosiego y malestar. Con sus hechos o con su muerte contribuye al advenimiento del desenlace trágico. Heroínas son Hormesinda y Lucrecia en Hormesinda y Lucrecia de Nicolás Fernández de Moratín; Raquel, en Raquel de García de la Huerta; Doña Ava, en Don Sancho García de Cadalso...

$\mathrm{El}$ poderoso. Suele transformarse en personaje principal, desencadenante de los hechos o determinante fundamental de su desarrollo. No es habitualmente ni positivo ni negativo, aunque hay excepciones. Se incluirían aquí Alfonso en Raquel, Orosmán en Xayra, Clitemnestra en Agamenón vengado, todas de García de la Huerta...

El caballero. Recibe pocos rasgos de caracterización. Puede convertirse en protagonista o, habitualmente, en personaje secundario. Puede ser positivo, y entonces es sensato, fiel, desinteresado; o negativo, con lo que es egoísta, servil... Es el encargado de transmitir una doctrina o una concreta visión de, o toma posición ante, la realidad. Nerestán, Lusiñán en Xayra; Cilenio en Agamenón y García, Manrique y Álvar Fáñez en Raquel, todas de García de la Huerta, encarnarían este tipo. 
El consejero. Aparece como personaje generalmente secundario. Hace las funciones de confidente, casi siempre fiel, y de acompañante. Es un personaje de diálogo. Puede determinar la actuación de los protagonistas y explicar las acciones que emprenden. Fátima, Corasmín y Chatillón en Xayra; Cilenio, Pílades, Fedra, Chrisótemis y Egisto (menos, pues no actúa como tal en la tragedia, aunque se alude a que desempeñó ese papel) en Agamenón vengado; y Garcerán, García, Álvar Fáñez y Rubén en Raquel toman cuerpo sobre este tipo, sobre esta función.

El mensajero. Se convierte en personaje secundario y, en ocasiones, puramente accidental. No recibe caracterización. Da a conocer determinados hechos o pone en contacto a algunos de los agonistas principales. Un soldado en Raquel que anuncia la llegada de García y Álvar Fáñez a la protagonista en la segunda jornada; Chrisótemis y Cilenio en Agamenón vengado; Lusiñán, Meledor y Esclavo en Xayra, se incluyen en este tipo.

El galán. Tipo secundario que nunca aparece exento sino adosado a otro principal. Es el encargado de desarrollar el tema de las relaciones amorosas. Alfonso y Orosmán serían gaianes en sus respectivas tragedias: Raquel y Xayra.

La dama. De igual característica y función al anterior, la encarnarían Hormesinda y Lucrecia en las tragedias homónimas de Nicolás Fernández de Mọratín; Raquel y Xayra en las tragedias homónimas de García de la Huerta; Solaya en la tragedia homónima de Cadalso...

Junto a estos tipos base aparecen en algunos textos, como acontece en Raquel en concreto, otros personajes carentes de tipificación funcional. Son personajes accidentales, grupos, personajes colectivos o colectivizados que no tienen ninguna individualidad, que forman parte del decorado de la tragedia e incluso tienen una intervención muda en ella. Son meros comparsas de los agonistas principales. Son la Guardia del Rey, los Castellanos y el Acompañamiento de Judíos y Judías.

En la tragedia neoclásica española observamos una tendencia bastante generalizada hacia el sincretismo. Los autores no siempre integran en cada agonista a un tipo funcional distinto. Varios de ellos pueden, e incluso suelen, confluir en un mismo personaje. Así, por citar sólo casos extraídos de las tragedias de García de la Huerta, Alfonso Octavo (Raquel) es poderoso, héroe y galán. Orosmán (Xayra) es poderoso, héroe y galán. Raquel (Raquel) es heroína, poderoso y dama. Clitemnestra (Agamenón) es heroína y poderoso. Xayra (Xayra) es heroína y dama. Egisto (Agamenón) es poderoso y consejero. Lusiñán (Xayra) es caballero y mensajero. Cilenio (Agamenón) es caballero, consejero y mensajero. García, Garcerán y Álvar Fáñez (Raquel) son caballeros y consejeros. Chrisótemis (Agamenón) es consejera y mensajera.

No obstante, en ocasiones existe una casi total correspondencia entre tipo funcional y personaje concreto. Rubén en Raquel es consejero. En Agamenón vengado, Orestes es héroe; Electra, heroína; Fedra y Pílades, consejeros. En Xayra, Nerestán es caballero; Fátima, Corasmín y Chatillón, consejeros; Meledor y el Esclavo, mensajeros.

Hallamos sincretismo funcional generalmente en los personajes principales y, como mucho, en los secundarios. No es habitual encontrarla en los accidentales. Con ese sincretismo los autores consiguen simplificar la composición de sus tragedias, cumpliendo así uno de los preceptos de la estética neoclásica que pedía pocos personajes y funcionales, tal como antes afirmábamos y como queda recogido en La Poética de Luzán: 
(...) Debe, pues, el poeta arreglar con juicio el número de actores y reducirlos a los menos que se pueda, para facilitar la representación, pues de otra suerte sería preciso hacer levas de farsantes como de soldados. A mí me parece que el número de ocho u diez personas será bastante y tolerable; lo que pase de ahí, será exceso y confusión (Luzán 1977: 514-5).

Con ello se facilita al espectador, en consecuencia, la labor de seguir el argumento de la pieza y el contenido que en él se incluye.

En muchas ocasiones los dramaturgos limitan la inclusión de tipos en los personajes principales de sus obras. Insertan, por ejemplo, un solo héroe, una sola heroína (si aparecen dos, como en Agamenón vengado, una de ellas es secundaria -Clitemnestra en este caso-), un solo poderoso (si figuran dos, como en Agamenón, uno es accidental -Egisto frente a Clitemnestra-). Los autores parecen no desear dispersar el protagonismo en las tragedias. Querer que ese papel principal lo asuma un número reducido de agonistas con el fin de mantener en el desarrollo del argumento una claridad expositiva general. En los personajes secundarios la situación varía. Un mismo tipo se puede multiplicar. Hallamos, por ejemplo, en García de la Huerta, varios caballeros y consejeros en Raquel; varios caballeros y consejeros en Xayra; varios consejeros en Agamenón.

Por la importancia de su intervención en la tragedia, por su contribución en el desarrollo general del argumento, los personajes pueden ser escindidos en tres grupos. El primero estaría formado por los personajes principales, por los protagonistas, aquellos cuya misión específica es el desarrollo básico de la acción. El segundo, por los personajes secundarios, encargados de cubrir diversos cometidos, posibilitar la aparición de incidentes, crear efectos dramáticos. El tercero, por los personajes que tienen una intervención circunstancial en el argumento, un cometido muy específico, cumplido el cual suelen desaparecer; o por aquellos que prácticamente forman parte de la ambientación de la pieza.

Los protagonistas suelen ser los personajes sobre los que se proporciona más datos al espectador. Son, generalmente, los más caracterizados y los que más funciones desempeñan, acumulando, incluso, algunas que son típicas de los otros grupos, como puede ser el enlace entre escenas mayores o menores para evitar dejar el escenario vacío, una de las preocupaciones básicas de los neoclásicos. En ellos se puede producir ese sincretismo de tipos al que antes nos referíamos. Se incluirían en este grupo Pelayo, Hormesinda, Munuza, en Hormesinda de Nicolás Fernández de Moratín; Raquel, Alfonso y García, en Raquel; Orestes, Electra y, menos, Clitemnestra en Agamenón vengado; Xayra y Orosmán en Xayra, las tres tragedias de García de la Huerta...

De los personajes secundarios se dan todavía bastantes rasgos de caracterización, pueden "padecer" el sincretismo de tipos y suelen cumplir un número de funciones relativamente elevado. Tal acontece, centrándonos en García de la Huerta, con Manrique, Álvar Fáñez y Rubén en Raquel; Cilenio, Pílades, Fedra, Chrisótemis y Egisto, menos, en Agamenón vengado; Fátima, Nerestán, Corasmín, Chatillón y Lusiñán en Xayra.

Los personajes accidentales carecen de caracterización. Suelen ser minoritarios en las tragedias. Así, en Huerta existen tres en Raquel: Guardia, Castellanos y Acompañamiento de Judíos y Judías, y dos en Xayra: Meledor y Esclavo.

Para contribuir al desarrollo del argumento y facilitar la transmisión del significado, del mensaje, de la enseñanza, los personajes suelen ser divididos en dos grupos antitéticos, los buenos y los malos, los racionales y los irracionales, los que saben cumplir con su obligación 
y los que hacen dejación de la misma, en definitiva, los positivos y los negativos, los portadores de conductas defendidas y dignas de imitación y los que encarnan conductas vituperables y dignas de rechazo. Se utilizan para ello, aparte de paralelismos y antítesis, los recursos básicos de las oposiciones binarias y los enfrentamientos duales a los que antes nos referimos. Con todo se efectúa el diseño del plano del contenido de la tragedias, de los temas que se plantean y sobre los que se desea adoctrinar al espectador.

\subsection{El tema y los temas}

Diversos contenidos se insertan en las tragedias neoclásicas españolas. Así el amor, el honor, las relaciones paterno-filiales, la libertad, la patria, el estado, la monarquía, el destino...

Cada uno de los temas no suele incluirse aislado de los demás. Suelen aparecer relacionados, incluso formando dos de ellos parejas antitéticas. Así, amor frente a obligación; amor frente a patria... Ellos, de tal forma diseñados, son la fuerza que se superpone a los personajes y los hace llevar una determinada línea de actuación, los hace debatirse, los hace sufrir, consiguiendo que aparezca la auténtica tragedia.

El amor se presenta como un sentimiento racionalizado, no impulsivo. La falta de racionalidad lo convierte en sentimiento negativo, conflictivo, fuente de desventuras, como acontece en Don Sancho García, en Solaya de Cadalso o en la propia de Raquel, de Vicente García de la Huerta. Debe ceder paso siempre ante nociones consideradas superiores como la patria, el estado, la institución monárquica o, en definitiva, la obligación.

El honor es uno de los valores que forman parte de la personalidad del héroe o la heroína trágicos. Provoca y justifica su comportamiento. Se une a conceptos como el patriotismo. Así, en Hormesinda, la heroína se vale de honor y patriotismo para vencer a Munuza. Por otro lado, como explica Antonio Mendoza:

\footnotetext{
[...] el honor en la tragedia neoclásica fue una virtud de proyección social, con finalidad en el pueblo mismo; no fue sólo un concepto personalista que concluyera en la satisfacción del individuo, sino que el hombre concreto y su carácter fuera el medio para que ese honor le calificara y a la vez beneficiara a su pueblo, el que, a su vez, era susceptible de ser honrado por sus acciones (Mendoza 1981: 384).
}

Las relaciones paterno-filiales son opuestas a nociones de hondo calado, como patria, obligaciones de vasallaje, responsabilidad de un gobernante. La gran noción, como no podría ser menos, prevalece sobre el aspecto más personal que supone las propias relaciones paterno-filiales. Tal sucede en Guzmán el Bueno de Nicolás Fernández de Moratín, o en Idomeneo de Cienfuegos, en las cuales el deber y la responsabilidad de los héroes como padres, ceden paso ante su deber y su responsabilidad como gobernantes.

La libertad recibe un enfoque social, nacional, no individual al estilo romántico. Se lucha por la libertad colectiva, por la independencia nacional, presentando, incluso, como en Numancia destruida de López de Ayala, casos de resistencia ante el invasor. Queda, pues, en muchas ocasiones, ligada al tema de la patria y del estado.

La patria y el estado son presentados como valores absolutos ante los cuales ningún otro puede prevalecer. Se muestra cómo el hombre debe ser útil a la sociedad, cómo debe 
siempre anteponer sus deberes como ciudadano a cualquier otra consideración personal. En este sentido puede hablarse, como ha hecho Andioc, de la tragedia neoclásica española como literatura comprometida (1976: 381-418). En los textos se suele mostrar cómo la patria sufre algún tipo de agresión. El héroe debe entonces intervenir en favor y defensa de la misma, dejando a un lado cualquier otro tipo de consideraciones.

La monarquía se halla en el centro de muchas de las piezas. Se hace una exaltación de la monarquía absoluta, pero entendida tal como lo hace el despotismo ilustrado. El monarca es presentado como un gran padre de familia, cuyo poder viene de Dios y que se preocupa por sus hijos (súbditos) y procura su bienestar. El rey puede tener comportamientos equivócados. Pero se explican por intervenciones, como en Raquel, de agentes externos. La eliminación de tales intervenciones provoca que el monarca asuma de nuevo su papel con absoluta normalidad.

Él destino se convierte en muchos casos en el justificador de los sucesos. Se une al tema de los cambios de fortuna. Puede ser el responsable del final trágico de los personajes. Tiende siempre a racionalizarse, no a convertirse en la fuerza ciega que figura en la tragedia clásica.

En definitiva todos los temas no son sino un instrumento usado por los neoclásicos para impulsar el nuevo modelo de sociedad y de ciudadano que defiende en España la Ilustración. El enlace, ante ello, con el significado es más que evidente.

\subsection{Significado}

La tragedia tiene un fin utilitario. Es evidente, tras lo expuesto. Pretende impulsar la idea de que la pasión -el instinto- debe siempre ser sometida a la razón y la obligación. Pretende enseñar ejemplos de comportamiento, con implicaciones muchas veces políticas, para el gobierno de los pueblos (enseñan a ser buen gobernante, a ser buen súbdito, buen ciudadano, a ser buen servidor del país...). Busca mostrar las consecuencias de todo tipo que pueden derivarse de determinadas líneas de actuación. Pretende utilizarse como medio de impulsar la transformación, en un sentido u otro (depende de la postura sustentada por cada autor), del país. Los hechos y los personajes son convertidos en modelos que indican cómo se debe o no se debe obrar. El didactismo es una de las bases de construcción de las obras. Las tragedias son textos de tesis cuyo proceso de construcción suele ir de la definición a lo definido. Se parte de una idea que se quiere transmitir. Esa es la definición. La composición del texto se orienta a conseguir ese objetivo y el argumento, lo definido, se convierte en ejemplo, en ejemplificación de la idea que se procura trasladar al espectador.

\section{La varia fortuna de una poética: en torno a la trayectoria y evolución del género}

Es la tragedia neoclásica española uno de los géneros neoclásicos que produjo un mayor número de textos ${ }^{8}$. Menos, tal vez, que la comedia sentimental, largamente cultivada debido al proceso de popularización al que se vio sometida y que en otro lugar estudié (Cañas 1994); más que la comedia de buenas costumbres dieciochesca. En su historia, en su trayectoria, podríamos distinguir tres etapas fundamentales. 
La primera de ellas sería la de la fundación del género, la de los orígenes. Comienza en 1750,1753 , fecha en la que se inicia la poética en las dos piezas que Agustín Montiano incluye como ilustración a sus dos Discursos sobre la tragedia, Virginia (1750) y Ataulfo (1753). Es una época en la que el género aparece en manos de críticos bienintencionados, no de dramaturgos, y los textos reflejan esta circunstancia. Son frecuentes las imperfecciones en la composición de las piezas, que no acaban de aquilatar completamente la preceptiva que pretenden extender. Las obras se difunden por la imprenta, pero no llegan nunca a ser representadas.

La segunda etapa transcurriría entre 1753 y los primeros años del siglo XIX (podemos elegir, convencionalmente, el año 1808, inicio de la guerra de la Independencia, como tope). Es el momento de consolidación del género. Los textos empiezan a sucederse, debido al impulso que recibe su serie, el género, por parte de los intelectuales del período, que emplean todos los medios que tienen a su alcance -tertulias (recordemos el importante papel que desempeñó la de Olavide, para la cual Jovellanos compuso su Pelayo), academias...- para difundirlo y extenderlo. Así, a través de la producción dramática de Nicolás Fernández de Moratín (Lucrecia de 1763, Hormesinda de 1770, Guzmán el Bueno de 1777), en primer término; a través de las piezas de López de Sedano (Jahel de 1763), Jovellanos (Pelayo o La muerte de Munuza de 1769), Cadalso (Don Sancho García de 1770, Solaya o Los Circasianos de 1770), López de Ayala (Numancia destruida de 1775), García Malo (Doña María Pacheco de 1788), Cienfuegos (Pítaco de 1792, Idomeneo de 1799), Merás Queipo de Llano (Teonea de 1797), Quintana (Pelayo de 1805) o el propio García de la Huerta (Raquel de 1778, Agamenón vengado de 1779, Xayra o La fe triunfante del amor y cetro de 1784). Es el momento en el que Aranda accede al poder y pone en práctica un plan de renovación de la dramaturgia de la época. Es el momento en el que, gracias a la sucesión de textos, se perfila la poética, se fijan definitivamente los constituyentes, se llevan a las tablas un buen número de creaciones que ya no solo de difunden a través de la imprenta. Es el momento en el que las piezas se convierten en medio de extender la ideología ilustrada, de realizar una defensa de la obligación frente al deseo, de la razón frente al sentimiento, del interés público frente al privado. Es el momento en el que se estrena Raquel, considerada la obra cumbre de la tragedia neoclásica española.

La tercera etapa transcurre en los primeros años del siglo XIX, a partir de 1808, hasta poco antes de su mitad. Es el período de decadencia de un género que cada vez va progresivamente contando con menos cultivadores. Los textos dejan, en ocasiones, sentir el influjo de la guerra de la Independencia y presentan una España en lucha contra el invasor. La poética va sufriendo transformaciones que terminan por adulterarla gravemente. La normativa neoclásica se va incluyendo cada vez con más laxitud (en el uso de las unidades...). Los textos se apartan de los modelos iniciales y van cada vez más desembocando en un nuevo género, el drama romántico, que progresivamente cuenta con mayor aceptación y cuya poética, junto con elementos tomados de la comedia sentimental o de la comedia de espectáculo (Cañas 1991: 53-63) hereda rasgos de la tragedia. La obra dramática de Francisco Martínez de la Rosa (recordemos sus piezas La viuda de Padilla de 1814, Aben Humeya de 1830 o su texto más famoso, La conjuración de Venecia de 1830, a veces considerado ya drama romántico -pese a las innegables deudas que tiene con la tragedia neoclásica- o, al menos, obra de transición ${ }^{9}$ ) es perfecta muestra del momento que estamos comentando. Con todo la tragedia neoclásica española se extingue y termina por desaparecer. Su poética se adultera y se disuelve, aunque no sin dejar rastros y restos en el nuevo género, el drama romántico, al 
que se encomienda la misión histórica de sustituir y suceder a los géneros dramáticos del neoclasicismo español, y, en general, de la época de la Ilustración.

\section{Notas}

1. Cf. Francisco Lafarga (ed.). El teatro europeo en la España del siglo XVIII. Lérida: Universidad de Lérida, 1997. Vid., especialmente, Juan Antonio Ríos, "La tragedia francesa", pp. 63-85 y, en el "Catálogo de las traducciones", pp. 205-234 y 325-363.

2. Cf. John A. Cook. Neoclassic Drama in Spain. Theory and Practice. Westport, Connecticut: Greenwood Press, Publishers, 1974, reprint. Vid., especialmente, pp. 80-83 y 107-137.

3. Cf. Jesús Cañas Murillo, "Apostillas a una historia del teatro español del siglo XVIII", en Anuario de Estudios Filológicos, XIII, 1990, Cáceres, UEx., 1991, pp. 53-63. Sobre los géneros dramáticos españoles del siglo XVIII y su relación con la periodización de la época, véase mi trabajo "Sobre posbarroquismo y prerromanticismo en la literatura española del siglo XVIII (De periodización y cronología en la época de la Ilustración)", en El siglo que llaman ilustrado. Homenaje a Francisco Aguilar Piñal. Coordinado por Joaquín Álvarez Barrientos y José Checa Beltrán, Madrid, CSIC, 1996, pp. 159-169.

4. Tal acontece, por ejemplo, con la comedia de buenas costumbres, que además de Luzán, en su Poética, fue individualizada por preceptistas como Blas Nasarre ("Disertación o Prólogo sobre las comedias de España” -cf. Jesús Cañas Murillo, Blas Nasarre. Disertación o Prólogo sobre las comedias de España. Cáceres, UEx. (Trabajos del Departamento de Filología Hispánica, 7), 1992, pp. 43-101-), Nicolás Fernández de Moratín (por ejemplo, en la "Disertación" o prólogo a La Petimetra - cf. Nicolás Fernández de Moratín, La Petimetra. Edición, introducción y notas de Jesús Cañas Murillo. Cáceres, UEx. (Textos UNEX, 3), 1989, pp. 57-76-), Leandro Fernández de Moratín (en su escrito "Comedias. Discurso preliminar", por ejemplo - vid. Obras de Don Nicolás y de Don Leandro Fernández de Moratín. Ed. Buenaventura Carlos Aribau. Madrid, Rivadeneyra (BAE, 2), 1846, pp. 307-325-)...

5. Vid., en general, el capítulo "De la fábula simple e impleja, y de la agnición y peripecia”, pp. 469- 477.

6. La insistencia de Luzán en la "verisimilitud" es constante en todo el libro tercero de La Poética, como puede comprobarse en la tantas veces mencionada edición de Sebold (el libro tercero ocupa las páginas 389-551).

7. En nuestro trabajo "Tipología de los personajes en las tragedias de Vicente García de la Huerta" publicado en Revista de Estudios Extremeños (Simposio Internacional "Vicente García de la Huerta", XLIV, II, mayo-agosto 1988, pp. 349-377), ya adelantábamos, aplicadas solamente a las tragedias de García de la Huerta, conclusiones que ahora recogemos, ampliadas, en esta parte de nuestro artículo. No obstante, en el aspecto concreto de la tipología, matizamos algunos asertos allí vertidos.

8. Puede ello comprobarse consultando la abultada relación de los mismos que se inserta en las páginas de la clásica obra de I. L. McClelland, Spanish Drama of Pathos 1750-1808. Volume I: High Tragedy. Volume II: Low Tragedy. Liverpool: Liverpool University Press, 1970, 2 vols.

9. Los textos de Francisco Martínez de la Rosa ya marcan, en general, un claro enlace con el romanticismo. Esta situación es más notoria aún en La conjuración de Venecia, juzgada, insistimos, por algunos críticos, como drama romántico, pese a sus claras deudas y conexiones con la tragedia neoclásica, de la que mantiene bastantes caracteres aunque otros son paralelamente modificados. 


\section{Bibliografía}

Andioc, René. 1970. Sur la querelle du théâtre au temps de Leandro Fernández de Moratín. Tarbes.

1976. Teatro y sociedad en el Madrid del siglo XVIII. Madrid: Fundación Juan March / Castalia. Especialmente, capítulo VII, "La tragedia neoclásica”, 381-418.

Benítez Claros, Rafael. 1963. "La tragedia neoclásica española". Visión de la literatura española. Madrid: RIALP, 155-98.

Busquets, Loreto. 1990. "La tragedia neoclásica española y el ideario de la Revolución Francesa”. En: Loreto Busquets (ed.), 87-127.

Susquets, Loreto (ed.). 1990. Cultura hispánica y Revolución Francesa. Roma: Bulzoni Editore.

Caldera, Ermanno. 1991. "Il teatro del pathos e dell'orrore al principio dell'Ottocento: fedeltà ai canoni del classicismo e presentimenti romantici”. EntreSiglos, 1. Roma:

Bulzoni, 57-74.

1993. "De la tragedia neoclásica al drama histórico romántico: por qué y cómo". Entre Siglos, 2, Actas de Congreso Entre Siglos. Cultura y Literatura en España desde finales del siglo XVIII a principios del XIX. Bordighera, 3-6 abril de 1990. Roma: Bulzoni, 67-74.

Cañas Murillo, Jesús y Miguel Ángel Lama Hernández. 1986. Vicente García de la Huerta. Mérida: Editora Regional de Extremadura (Cuadernos Populares, 14).

1988. "Tipología de los personajes en las tragedias de Vicente García de la Huerta". Revista de Estudios Extremeños. Simposio Internacional "Vicente García de la Huerta”, Cuadernos de Estudios Extremeños, XLIV, II, mayo-agosto, 349-377.

1990. “Apostillas a una historia del teatro español del siglo XVIII". Anuario de Estudios Filológicos, XIII, Cáceres: UEx., 53-63.

1994. La comedia sentimental, género español del siglo XVIII. Cáceres: UEx (Trabajos del Departamento de Filología Hispánica, 14).

1996. "Sobre posbarroquismo y prerromanticismo en la literatura española del siglo XVIII (De periodización y cronología en la época de la Ilustración)". Homenaje a Francisco Aguilar Piñal. Coordinado por Joaquín Álvarez Barrientos y José Checa Beltrán. Madrid: CSIC, 159-169. 
Cerezo Rubio, Ubaldo y Rafael González Cañal. 1994. Catálogo de comedias sueltas del Museo Nacional de Teatro de Almagro. Madrid: Ministerio de Cultura-Universidad de Castilla-La Mancha.

Cook, John A. 1959. Neoclassic Drama in Spain. Theory and Practice. Dallas: Southern Metodist University Press. Reimpresión en Westport, Connecticut: Greenwood Press Publishers (1974).

Fernández de Moratín, Nicolás. 1989. La Petimetra. Edición, prólogo y notas de Jesús Cañas Murillo. Badajoz: UEx. (Textos UNEX, 3).

Fernández González, Ángel Raimundo. 1994. "Notas sobre la tragedia en la segunda mitad del siglo XVIII". Del horror a la risa. Los géneros dramáticos clásicos. Actas del Congreso Internacional. Universidad de Navarra, noviembre de 1992. Homenaje a Christiane Faliu-Lacourt. Eds. Ignacio Arellano, Víctor García Ruiz y Marc Vitse. Kassell, Reichenberger.

Herrera Navarro, Jerónimo. 1993. Catálogo de autores teatrales del siglo XVIII. Madrid, Fundación Universitaria Española.

Luzán, Ignacio de. 1751. La razón contra la moda. Comedia. Traducida del francés. Madrid: Joseph de Orga.

1977. La Poética. Reglas de la poesía en general y de sus principales especies. Edición, prólogo y glosario de Russell P. Sebold. Barcelona: Labor (Textos Hispánicos Modernos, 34), 433.

McClelland, I. L. 1970. Spanish Drama of Pathos 1750-1808. Volume I: High Tragedy. Volumen II: Low Tragedy. Liverpool: Liverpool University Press, 2 vols.

1975. The Origins of the Romantic Movement in Spain. A Survey of Aesthetic Uncertainties in the Age of Reason. Liverpool: Liverpool University Press.

Mendoza Fillola, Antonio. 1980. La tragedia neoclásica española. Barcelona: Universidad de Barcelona.

1981. “Aspectos de la tragedia neoclásica española”. Anuario de Filología, VII, 369-89.

1988. "El compromiso colonial y el despotismo en la tragedia neoclásica". Coloquio internacional sobre el teatro español del siglo XVIII. Bolonia '15-18 de octubre de 1985. Abano Terme, Piovan Editore, 267-88.

Millé Giménez, Isabel. 1930. "Guzmán el Bueno en la historia y en la literatura". Revue Hispanique, LXXVIII, 311-488. 
Montiano y Luyando, Agustín. 1750. Discurso sobre las tragedias españolas. Madrid: Joseph de Orga.

1753. Discurso II. Sobre las tragedias españolas. Madrid: Joseph de Orga.

Pageaux, Daniel-Henri. 1966. "Le thème de la résistance asturienne dans la tragédie néoclasique espagnole". Mélanges a la mémoire de Jean Sarrailh, III. París: Centre de Recherches de l'Institut d'Études Hispaniques, 235-242.

Palacios Fernández, Emilio. 1988. "El teatro en el siglo XVIII (hasta 1808)". Historia del teatro en España, II. Dirigida por José María Díez Borque. Madrid: Taurus, 57-376. cf., especialmente, "La tragedia", en pp. 194-201.

Palacios Fernández, Emilio. 1996. "Teatro”. Historia literaria de España en el siglo XVIII. Edición de Francisco Aguilar Piñal. Madrid: Trotta-CSIC, 135-233. cf. especialmente, "La tragedia neoclásica", en pp. 193-200.

Ríos Carratalá, Juan A. 1986. "La historia nacional en la tragedia neoclásica”, en VV. AA., La Ilustración española. Actas del Coloquio Internacional celebrado en Alicante. 1-4 octubre 1985. Ed. de A. Alberola y E. de la Parra. Alicante: Instituto Juan Gil-Albert. Diputación Prov. de Alicante, 189-196.

Sala Valldaura, Josep Maria. 1994. "Los jesuitas expulsos y la tragedia entre España e Italia". Bulletin Hispanique, 96, 1, janvier-juin, 153-166.

1994. "La felicidad social como virtud en la tragedia neoclásica". Castilla, 19, 171-186.

Sánchez Blanco, Francisco. 1991. "Guzmán el Bueno, ¿un arquetipo para el hombre ilustrado? Tratamiento dramático de un mito nacional". Spanien und Europa im Zeichen der Aufklärung. Internationales Kolloquium and der Universität Duisburgvom 8-11. Oktober 1986. Ed. Siegfried Jüttner. Frankfurt / Main, Peter Lang (Europäische Aufklärung.in Literatur und Sprache, Band 2), 228-244.

Tietz, Manfred. 1989. "La figura de Lucrecia la romana vista por la Ilustración española y alemana”. Reyes Mate y Friedrich Niewöhner (coord). La Ilustración en España y Alemania. Barcelona: Anthropos (Pensamiento crítico/Pensamiento utópico, 40), 71-93.

VV. AA. 1996. Teatro español del siglo XVIII. Contiene diversos ensayos, exámenes y lecciones críticas varias sobre dicho sugeto, compuestos por ingenios de Esta y otras Ciudades. Editados con recocijo por el corto Numen de D. Joseph Maria Sala Valldaura, atento Recopilador de los solemnes actos que hubo en la ilustre ciudad de Lérida en el año de M.CM.XCIV. Lérida: Universidad de Lérida, 2 vols. 
